\title{
Witnessing outsider witnessing: A reciprocal witnessing workshop with young people reclaiming their lives back from pain and fatigue
}

\author{
Deborah Christie*, Fiona McFarlane, Lucy Casdagli and Glenda Fredman \\ University College London Hospitals, UK
}

The adolescent unit at University College Hospital London works with young people whose lives have been knocked off track by symptoms of pain and fatigue. What may have started as a minor illness or injury increases in severity until the young person is unable to sit up or speak in more than a whisper and may find even the touch of bedclothes excruciatingly painful. The pain and fatigue often bring with them symptoms of nausea and intolerable insensitivity to light and sound. Many young people have told us that they have received "no understanding" and been treated with disbelief and criticism because there has been no medical diagnosis to give credibility to their experience. This paper tells the story of a reciprocal witnessing workshop adapted from outsider witnessing practices [1,2] for a group of young people who were previously in treatment and those who are currently in treatment on the adolescent unit.

\section{Our hospital context}

University College London Hospital (UCLH) is a large public health service hospital in London, England. Our clinical psychology team works alongside the medical team of doctors, nurses, physiotherapists and occupational therapists with children and young people affected by different physical illnesses, including diabetes, arthritis, cancer and gastric conditions. Our team works with a systemic approach to help these young people and their families manage the challenges created by these illnesses. Solution focused, narrative and motivational interviewing approaches are regularly integrated into our practice [3].

Young people affected by debilitating symptoms of pain and fatigue for which doctors have not found standard (diagnostic) explanations are frequently referred to our service. In this paper we tell the story of a workshop we facilitated for young people affected by these sorts of symptoms. We will go on to explain how we made use of experience consultants [4] and outsider witness practices [5] and describe the effects of the workshop on the young people who took part. We will highlight how the workshop provided an opportunity for young people designated as 'patients' in the hospital to hear and share stories of resilience with other young people invited as the experience consultants because they had worked with us in the past and found ways to get their lives back on track. A process of mutual witnessing between these two groups ('young people' and 'experience consultants') opened space for stories of hope to be told and lived.

Fatigue and pain trouble many young people with a third of adolescents reported as complaining of substantial fatigue four or more times a week [6]. With some young people the fatigue and pain take an upper hand and prevent them from attending school or getting on with their lives. When extensive medical investigations fail to find a cause for the pain and fatigue, the symptoms often start attracting labels such as 'psychosomatic' or 'conversion syndrome' and are construed as 'unreal' or 'imaginary'. These labels can direct young people and families towards traditional mental health treatment services where treatment models might assume that a psychic trauma has triggered the symptoms or that the symptoms are 'functional'. Therapy is therefore directed towards uncovering the event that the young person and their family are presumed unable to describe or speak about and often limits access to other treatments of the physical symptoms by physiotherapy or occupational therapy.

Because of poor outcomes within mental health settings, some teams have started providing treatment involving emotional, physical and relational interventions within multidisciplinary medical systems. We participate in this sort of multidisciplinary approach at UCLH. The discourses informing systemic and narrative approaches differ from the traditional medical discourse that uses the language of diagnosis, designates young people as 'patients' and assumes that medical tests can objectively distinguish the 'reality' of symptoms. Therefore as psychologists working systemically with colleagues within a medical setting, we try to find ways to join respectfully with the team and introduce different ways of thinking about and talking with the young people and families we work with which is not too unusual for our colleagues yet also affirming and appreciative of the young people's perspectives [7].

\section{Narrative principles informing the workshop}

Like Michael White [5] we hold that we live our lives according to the stories we tell ourselves and the stories we are told by others [8]. These stories talk to us of who we are, who we were and who we can become. Thus our stories are constitutive, both forming and informing our identities. Illness, pain and fatigue tend to dictate the sorts of stories told of and by the young person. Michael White [5] described our sense of self as a 'territory of identity'. He explained how problems like trauma can act to shrink this territory, our sense of who we are, thereby disconnecting us from our abilities to influence our own lives and those of others. Without a sense of who we are it is difficult to go on, to make decisions, to dream of our future, since to participate

Correspondence to: Deborah Christie, University College London Hospitals, UK, E-mail: DEBORAH.CHRISTIE@uclh.nhs.uk

Received: August 25, 2016; Accepted: October 17, 2016; Published: October 20,2016 
in these life affirming activities, we need to be standing on the safe ground of who we are. We have seen how Pain and Fatigue - especially when teaming up together over many years - can not only shrink but also sometimes even erode the territory of identity of young people. Fatigue often works in tandem with Pain to pin young people to 'sick' beds for extensive periods of time thereby isolating them from many of the experiences of their peers such as school, social life and family. The young people we work with often speak of how Pain, Fatigue and Illness take over their lives to the point of defining who they are, for example "a sick person", "a patient"; "a CF person".

Narrative practices involve enabling people to tell stories about their lives in ways that make them stronger $[9,10]$ or enables them to go on. The process of externalising 'pain' and 'fatigue' enables young people's to begin to separate problems from their identity and move towards a richer description of their lives. For these stories to live and breathe they also need an audience. Pain and Fatigue often disconnect young people from audiences to the stories they want told about themselves and who might witness and appreciate their preferred versions of self. Even when preferred stories begin to emerge in therapy, they are often witnessed by only a therapist and one or two family members and therefore risk remaining fragile. The Narrative approach offers practices to extend the audience to these stories through the use of certificates, letters and celebrations [11-13]. Outsider witnessing also offers the opportunity to invite an audience to witness preferred identity stories.

\section{Outsider witness practices}

Inspired by Barbara Myerhoff's [14] work with older Jewish people in California, Michael White developed outsider witnessing practices, which create opportunities to invite an audience to witness people's preferred identity stories [1]. In outsider witnessing one or several people are invited to join a session. In the first instance the witnesses are asked to listen whilst the interviewer interviews the 'clients', creating space for the telling of preferred identity stories. Then the clients are invited to listen as the interviewer interviews the outsider witnesses.

The interviewer is typically guided by four types of 'outsider witness' questions that invite the witnesses to 1) select something the client has said that was particularly meaningful to the witness (Identifying the Expression); 2) say something about the image this phrase or expression evoked for the witness of what was important to the client (Identifying the Image); 3) make connections between their own values or experiences and that of the clients (Embodying Responses), and 4) reflect on how they have been influenced by the clients' story and what contribution it makes to their own future life (Acknowledging Transport). Finally the interviewer invites the 'clients' to comment on what they have heard from the witnesses $[2,15]$.

The intention of outsider witness questions is to bring forth detailed personal links to the client's preferred ways of living and to thicken the under-noticed narratives of their life. Michael White talks of how the witnesses' response to the 'Transport' question (eg How is your life / work different for what you have heard today?) is particularly important. Many people who have experienced trauma or other overwhelming problems in their lives have very little sense of influence on their own lives or the lives of others. Hearing the impact that their story has had on others and the contribution their story makes to others' lives can be a validating experience that opens space for further positive developments of self $[2,16]$.

\section{The origins of the workshop}

All the young people on the adolescent in-patient ward at UCLH have the opportunity to attend a weekly therapeutic group that aims to provide a forum to discuss issues related to both illness and adolescence [17]. When we evaluated the group, the young people fed back that they liked meeting others like themselves who were living with similar symptoms or conditions. They said they would also like to meet with young people who were further along the journey of recovery than they were. It was from their feedback that the idea of the witnessing workshop was born.

We asked our multidisciplinary hospital team to help us identify experience consultants who had previously used our service and current 'patients' who might like to meet with them. We planned to follow the conventional outsider witness practice of interviewing the patients (whom we will now refer to as 'young people') so they could share their stories; then inviting the experience consultants to act as outsider witnesses, and finally inviting the young people to reflect on the effects of listening to the experience consultants. When we explained this process to the young people the day before the workshop, however, they told us that they preferred to have the experience consultants talk about their experience first rather than only tell their own. Therefore with short notice and the agreement of the experience consultants, we decided to adapt the traditional outsider witnessing format and created what became a 'reciprocal witnessing' session.

\section{The reciprocal witnessing workshop}

Three young people with varying degrees of chronic fatigue and chronic pain syndrome $(\mathrm{H}, 17 ; \mathrm{A}, 17 ; \mathrm{G}, 16$ and four experience consultants (two with juvenile idiopathic arthritis, T,20; R,23 and 2 with chronic pain, L,18; S,19; participated in the workshop. Deborah convened the workshop and in addition Fiona and the ward social worker, who both co-facilitated the young people's group on the ward, joined the young people. The session was held in the schoolroom on the ward. Two of the young people were inpatients and were bedbound $($ A \& $\mathrm{H})$ and another used a stick to help her walk $(\mathrm{G})$. One of the experience consultants came in a wheelchair (L).

We began with interviewing the experience consultants about the steps they had taken to reclaim their lives from Pain and Fatigue. Then we invited the young people to respond to the stories of the experience consultants using version of the outsider witness questions presented in Table 1. We went on to interview the young people about their experiences, following a reauthoring interview map [1,2] to bring forth their preferred identity stories. Finally we invited the experience consultants to witness the young people's stories. We then reflected on the process together, positioning the all the young people as experts to feed back to us about their experience.

\section{Preparing the experience consultants}

We were aware that exhaustion and pain can limit the amount of time young people can participate before needing to rest. Therefore to ensure sufficient time to give everyone a chance to speak, we invited the experience consultants into the room first to explain how we would work. Deborah checked if they would be willing to begin sharing their own experiences and have the young people respond to this. She also gave them a 'preview' of the questions she we would be asking them (There was also the opportunity to try these questions out through an example interview. Deborah interviewed Fiona about her work with young people and then asked the experience consultants the outsider witnessing questions, allowing the opportunity to de-brief afterwards).

\section{Interviewing the experience consultants}

After the young people joined the workshop and all had introduced 
Table 1. Examples of Outsider Witness Questions we asked.

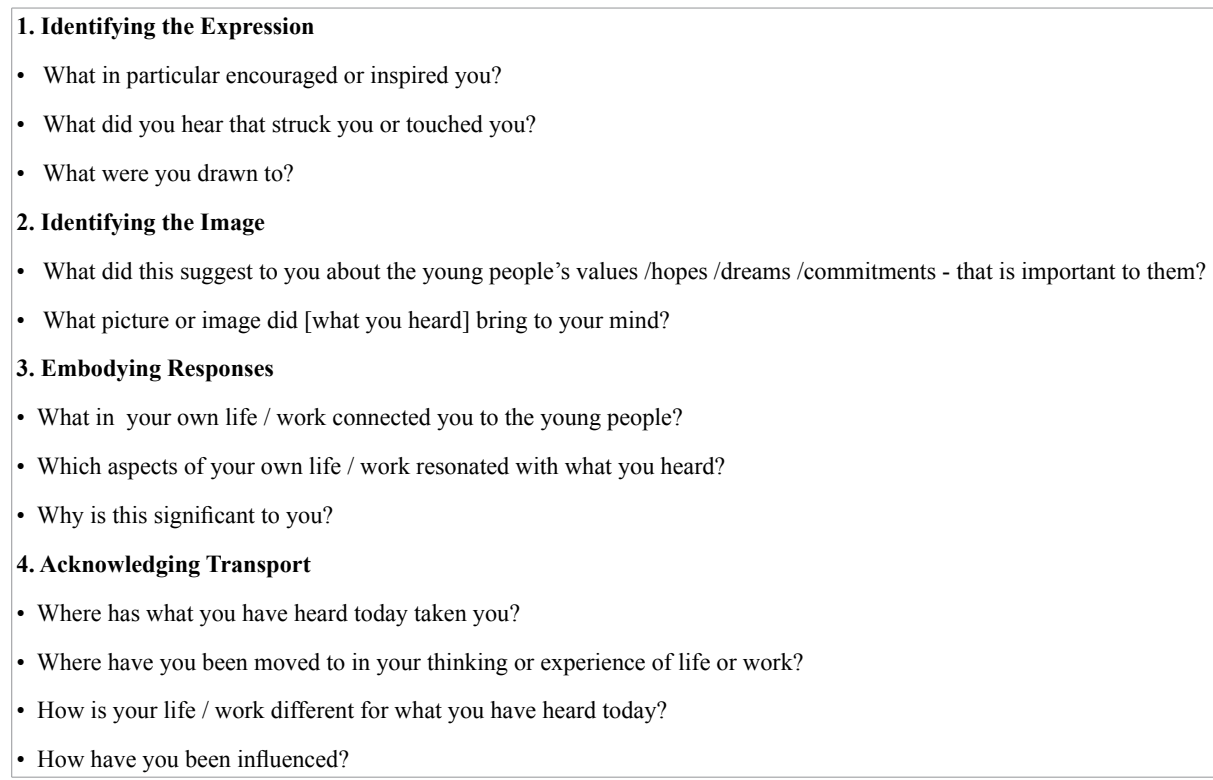

themselves, Deborah invited each experience consultant to tell the story of how the pain had come into their lives; how they coped when things had been when at their worst; how they came to be involved with the hospital team, and how the situation was currently.

(Could I ask you to tell everybody a little about when you first came to UCLH and why you came here? How did you end up on the ward? What was your lowest point? Where are you at now? So what are you doing now?)

With the intention of bringing forth stories of coping, survival, achievements and positive developments in their lives, Deborah went on to invite the experience consultants to explain how they had made these steps of progress, what skills and personal resources they had drawn on in order to do this and their hopes for the future. (Do you remember that journey? What was it that helped you to get to the point you are at now? I am curious about, when you were on the ward and going through treatment and kind of struggling in different ways with it all: what helped you to keep going? What most helped when you were really in that worst place? So, when you look back from your position now, what were the skills you used to keep yourself going? What helped move you over into getting your life back? What are your plans for the future?).

\section{The experience consultants share their experiences}

The experience consultants told stories of how they had had to cope not only with extreme physical pain but also with aversive consequences of their symptoms such as social isolation, bullying, depression and anger: "When I was at school I got really badly bullied because I couldn't do the same things as everyone else"; "I lost a lot, a hell of a lot of friends."

They all had experiences of misdiagnosis and not being believed: "I went through ten years of hell not being diagnosed ... being told I was anorexic and bulimic; my mother was a neurotic mother and I was attention seeking"; "I cried when they told me I had arthritis. It wasn't because of what I got, I didn't even know what it was ... but it was sheer relief, of 'Oh my gosh, somebody actually believes me now"; "You get a lot of trouble with friends and family and doctors because they don't understand it."
They described how pain took over their lives and made it harder to live how they wanted, making developmental tasks of adolescence such as sitting public exams and developing independence much harder. They described their frustration at how their world was very different from that of "normal" adolescents, often being unable to participate in social or educational activities that were important to their peers: "I used to spend the vast majority of my time, at the hospital - in my wheel chair, in bed sometimes could be eight months at a time. ..."; "It was a really, really, really, really, really traumatised moment for me, because it took over my life when I was eighteen." "I was meant to be out and about, doing what normal, in quotation marks, sixteen year olds do. And I couldn't, because I was in hospital"; "I was doing my A levels at the time, so also I was worried about that."

They experienced the early stages of their hospital stays and treatment as particularly aversive: "I think the whole thing was very hard"; "I spent the majority of time in an adolescent ward in floods of tears"; "I didn't really think anything was helping me in the hospital ward."

Despite these experiences, they had all been to, or were on their way to university. Three of them had part time employment, and they all had activities or hobbies they pursued, from photography to dancing on tables! All four of them described some on-going symptoms of pain or fatigue but the interference of these symptoms in their daily life was much reduced. Seeing other young people relating with their doctors differently helped them find new ways of being with doctors to achieve the outcomes they wanted. They said letting people in was a very gradual process of "taking the bricks of (my)defences off one by one" and letting those working with them "see the real me".

They highlighted a variety of skills, values and attitudes to life that had supported them on their journey to this new place. "Holding on to what (they) wanted" in their mind and "remembering what I had" helped them through the harder times. Qualities of "stubbornness" and a "sense of humour" and skills such as "using anger in a positive way" had helped them take steps forward as well as "seeing there are people worse off .... because it reminded me of what I had" and refusal to "be stuck in a hospital ....., because I felt I'd wasted far too much of my life as it was." 


\section{Young people responding to the experience consultants stories}

Deborah invited the young people to witness the experience consultants' stories using questions like those in Table 1 . We kept this part of the session relatively short to ensure enough time for a fuller witnessing of the young people's own stories.

All three young people were struck by the similarities between their own experiences and those of the experience consultants. They connected with the stories of progress made by the experience consultants and described how this had moved them to feeling "optimistic", more "hopeful", and more positive about the future: "It's all very similar really"; "I'm stuck in bed at the moment and it's good to hear that a lot of you are sort of walking, starting to get back to normal"; "I feel quite optimistic because I always thought you meant to do your education when you are like this age and, no-one ever goes to uni when they are older than they should be ... but I sort of realise you don't..... There's the rest of your life and you can do it, You just maybe do it a few years later or something, or spread over a period of time."

\section{Interviewing the young people about their experience}

The young people described feeling a sense of hope from hearing the stories of the experience consultants. This seemed to show itself immediately since they started speaking of the progress they had already made when relating their own experience.

Each young person was asked "What were the reasons that you came to UCLH, what were the things that were stopping you getting on with your life?"

After a brief description of the symptoms that had brought them into hospital Deborah then asked "may I ask you to tell me a little bit about what you feel has gone well in the last 2 years?"

The three young people talked about the developments they had made since first becoming ill. They told of steps they had already taken to claim back their lives from pain and described additional steps they were intending to take in the future. For example: "I' $m$ hoping to get into a wheel chair in about two or three months' time, which is a really big step because last time I was in a wheel chair was about two and a half years ago.", "Right now I'm, I've just begun recovering. I was diagnosed with chronic fatigue syndrome a couple of months ago and the illness started last year ... probably worst around Christmas... after my exams finished I started getting better"; "I started physiotherapy and I'm hoping to be walking without the stick in about a month"; "I used to have, well I've still got it a bit,....chronic fatigue and I used to be very tired a lot of the time. That's got a lot better. The movement in my legs has got considerably better than it used to be. It got a bit, not a lot, but a bit less sensitive and just we're slowly making improvements."

Many of the challenges the young people described were similar to those raised by the experience consultants, such as the experience and impact of 'not being believed' or 'being misdiagnosed': "When I went to either the GP or the local hospital, they didn't really know what was going on"; "At my local hospital I was told that I'd never get better and I'd be like this the rest of my life and that I'd be bed bound and never walk and so it was quite hard"; , "There were some doctors who weren't so helpful. When I first told one doctor I've been having pain for a couple of weeks and its really quite bad and I sometimes have difficulty doing normal tasks, she just dismissed it as sleeping pains, sleeping wrongly and having pain from that and she just didn't listen to me"; "I had people like that, who didn't really understand that my situation wasn't normal, it wasn't a short-term thing."

We were struck by the young people's desire for getting on with life and wish for independence. This was a powerful motivating force which they described as being key in keeping them going whenever it felt like pain was trying to get the better of them:, "I think [recovery] it's partly to do with, as a person, I'm quite like $R$ [one of the experience consultants] quite stubborn and quite determined to get on with things as normal. And I always wanted to live a normal life"; "I just wanted to get back to where I was a year and half ago and remembering the peak that I was at then gives me the drive to carry on and persevere"; "I've just been determined to get better and get on with my life and I know there's lots of things out there to look forward to so I just keep aiming for them"; "I just, I really just want to get back to being where I used to be. Just being able to do things independently.... go outside, you know, go do some stuff by myself."

All the young people appreciated the different contributions from the multidisciplinary hospital team: "the help of the physiotherapists and occupational therapists and psychologists has been helpful"; "generally the help I've had with psychologists, paediatricians, physios has all been really helpful". They appreciated the opportunity to acknowledge progress they were making as well space to discuss the effect of pain on their lives:

"Well my physio and OT did a graph of where I was and where I'd now got to. It helped me quite a lot because it gave me a bit of confidence to do a bit more. It showed me where I'd got to"; "I think everyone's support and encouragement, and positive approach really helped me, it allows me to have a different perspective"; I never really stopped and looked back on what my life, how my illness has been and any progress that I've made and any real lows in the time of my illness and the professionals have helped me to do that... that's been the most important thing, the aspect of their help."

\section{Experience consultants witnessing young people's stories}

Deborah went on to ask the experience consultants the four outsider witnessing questions (Table 1). For the sake of space we share here just a few of the ideas and responses that most stood out for us.

The experience consultants were again struck by similarities between their own and the young people's stories. They made connections with the physical symptoms the young people described, the challenges of coping with life in hospital and the dilemma of whether or not to accept help: “I got very choked up as I hadn't realised the impact my illness had had on me and still has on me on my daily life. It's a positive thing because on a daily basis I have to remind myself that I have to keep fighting I have to keep going on. I still have days that I refuse to get up"; It's, really hard I mean, bloody hell we've managed it quite well I hope (laughs)....you'll just have to deal with it in the end ...I'm still getting help from a counsellor and he's really good - don't make yourself think, if you need a counsellor you've got to be treated as a psycho or anything, believe me. I mean don't hold back, I mean, I held back for years. Saying no I'm fine, I'm fine, I can walk and then I try and walk and I'd fall over flat on my face and everyone laughs and goes 'You need help"'; "I've never felt sorry for myself, I always got up in the morning and made sure you know I spruced myself up, painted my face on, as everybody used to say. I'd be dressed like I was going out, so for me it was, you know just not looking ill. And trying to be normal, whether it was I just went to the end of the road, pushed in my 
wheelchair and back out again just to sort of, not feeling like I was in a prison."

Many of their images reflected hope. Joel described an image of hope, illustrated by Bob Marley singing 'don't worry...... about a thing...' The other experience consultants described that having the young people witness their progress and then having the opportunity to witness the young people's hopes for the future created a powerful image of hope for all of them.

All the experience consultants spoke of how the workshop had brought home for them just how far they had travelled on their journey despite being told in the past they would never achieve. They explained that they had become so used to the "battle and war" so that there was "no chance to look back at all the things [they had] achieved". Two spoke of how the witnessing made them feel "incredibly strong" and helped them realise they could "now face anything": "I didn't realise until today how far I have actually come";

Taking part in the witnessing workshop connected them with others in a similar position - they shared contact details with the other experience consultants thereby creating their own virtual 'anti-pain league' [18].

The experience consultants were still on their own journey themselves, continuing to find ways to live their lives in the context of the pain they were suffering. They talked about how the process of sharing their own stories and hearing the young people's responses had enabled them to reflect on their own lives and to gain a sense of their emotional strength: "It helps to remind me, to stay focused, to know where I'm going to, to keep me in the frame of mind of what I want to achieve and reminds me what I have achieved".

\section{Outcome of the reciprocal witnessing workshop: The Transport continues}

Since the workshop we have been privileged to see further signs of its effects and we share a couple of examples here. As G left the workshop she turned to Fiona and said, "When is the next one of these and please can I put my name down for it?" A few weeks later she arrived at her medical appointment with her walking stick neatly folded up in her bag, She had walked to the session without it for the first time and her progress continued over the following weeks such that she started back at school not long after that.

At a review meeting with our multidisciplinary team the mother of A who had attended the workshop a month before spoke of the "profound effect" the workshop had had on her son. She described how it had enabled him to talk to her about things he had never talked about before. The young person himself spoke of how reassuring he had found it to hear of others who had been in a similar situation and had "come out the other end".

We shared stories of the witnessing workshop in our multidisciplinary ward rounds. We shared quotes from the day that reflected perseverance, persistence, courage and hope. Members of the team including medical and nursing staff were intrigued to hear about the young persons' commitments to their futures as well as delighted to hear about the progress made by young people they had previously worked with. Sharing the sense of hope created in the workshop by all the young people offered encouragement and inspiration to team members who had not taken part.

Some of the experience consultants have gone on to join us presenting the reciprocal witnessing workshop at conferences and study days where we describe the principles informing the workshop and our experiences running it. A young person then shares their experiences with the audience giving the audience, positioned as outsider witnesses, an opportunity to practice the questions and experience answering them for themselves. We have had very positive feedback from participants on all sessions with comments about its impact on their personal as well as professional lives.

Conducting the reciprocal witnessing workshop and talking about it at conferences has had an impact on all of us as individuals and as therapists. It has reminded us that hearing stories of hope and the possibility of change from those who have been in a similar position and talk from experience is much more powerful than hearing it from 'professionals' or 'experts'. Witnessing how the transforming impact of this approach helpful it has been has moved us to think how to use the approach with different groups of young people and parents.

A vivid image that stays with us from the workshop is of 'passing the baton' evoked by L, one of the experience consultants, telling A, one of the young people, "I am handing over the baton to you, mate.... next time it will be you doing this job and some others will in your bed here". Three years later A has participated in 2 workshops as an experience consultant. Two further workshops have been run with different members of the team invited to join. Following the last workshop we created a word picture from the feedback the participants gave we used this image to create a thank you letter which we sent to all participants. We created this therapeutic document with the intention of capturing their words and to provide an opportunity to 'spread the news' through being able to share it with others [11-13]. Both the young people and experience consultants in all the groups have said that they would recommend the group to other young people. They described it as a 'motivational group, which gives you a push' and 'Story telling from different angles'. In terms of the process they reflected how it was helpful in 'talking about something in a very positive way' and 'a positive thing to encourage each other".

An unexpected consequence has been the positive effect the workshops have had on the outsider witnesses. The experience consultants were still on their own journey themselves, continuing to find ways to live their lives in the context of the pain they were suffering. They talked about how the process of sharing their own stories and hearing the young people's responses had enabled them to reflect on their own lives and to gain a sense of their emotional strength: "It helps to remind me, to stay focused, to know where I'm going to, to keep me in the frame of mind of what I want to achieve and reminds me what I have achieved". They have described the positive effects of how telling of their own stories in this way has helped them to realise how far they have come and reflect on the distance they have travelled since first joining the team. One of the experience consultants fed back that she 'found it really beneficial for my own journey' and another voiced 'it's nice to tell my story and it reinforces how far I've come and that a bad day is just a day, I'll get over it'.

They also reflected the importance of being able to be helpful to other young people through creating a context of giving hope for the future. They were struck by the strength in the young people whose stories they witnessed. They appreciated how 'Everyone is equal' and they felt 'privileged to hear the different positions'

We were struck by the comment of one of the outsider witnesses who reflected on what they had learnt about their journey. This powerful message resonated with the group, including the professionals 
that took part: 'Everything is going to be okay in the end but if it's not okay then it's not the end'.

\section{References}

1. White M (1995) Reflecting teamwork as definitional ceremony. In: White M (Eds.), ReAuthoring Lives: Interviews and Essays (pp 173-198). Adelaide, Australia: Dulwich Centre Publications.

2. Carey M, Russell S (2003) Outsider-witness practices: Some answers to commonly asked questions. International Journal of Narrative Therapy \& Community Work3-16.

3. Griffin A, Christie D (2008) Taking the psycho out of psychomatic: Using systemic approaches in a paediatric setting for the treatment of adolescents with unexplained physical symptoms. Clin Child Psychol Psychiatry 13: 531-542.[Crossref]

4. Walnum E (2007) Sharing stories: the work of an experience consultant. International Journal of Narrative Therapy \& Community Work 2: 3-9.

5. White M (1997)'Definitional ceremony.' In: White M (Ed.), Narratives of therapists' lives. Adelaide,, Australia: Dulwich Centre Publications, 93-114.

6. Viner R, Christie D (2005) Fatigue and Somatic Symptoms. In: Viner R (Ed.), ABC of Adolescence (pp. 42-46). Oxford: Blackwell Publishing.

7. Fredman G, Johnson S, Petronic G(2010) Sustaining the ethics of systemic practice in contexts of risks and diagnosis. In: Anderson E, Fredman G,Stott J(Eds.), Being with Older People: A Systemic Approach: London, Karnac Books, 181-210.

8. White M, Epston D (1990) Narrative means to therapeutic ends (1stedn), New York, NY: W.W. Norton \& Company.
9. Wingard B (2001) Introductions and Stories of Life. In:Wingard B, Lester J(Eds.), Telling our stories in ways that make us stronger. Adelaide,, Australia: Dulwich Centre Publications

10. White M (2006) Narrative practice with families and children: Externalising conversations revisited. In: White M, Morgan A (Eds.), Narrative therapy with Children and Families. Adelaide: dulwich centre publications.

11. Fox H (2003) Using Therapeutic Documents-A Review. International Journal of Narrative Therapy \& Community Work 4: 26-36.

12. Lunn S (2008) Spreading the News: Coping Tricks from the Sickle Cell Clinic! International Journal of Narrative Therapy \& Community Work 3: 41-46.

13. Freedman J, Combs G (1996) 'Shifting paradigms: From systems to stories.' In: Freedman J, Combs G (Eds.), Narrative therapy: The social construction of preferred realities, chapter 1. New York: Norton.

14. Myerhoff B (1982) Life history among the elderly: Performance, visibility and remembering. A crack in the mirror.Reflexive Perspectives in Anthropology 99-117.

15. White M (2002) 'Definitional ceremony and outsider witness responses.' Workshop notes: www.dulwichcentre.cau August $23^{\text {rd }} 2002$.

16. Denborough D (2008) “Collective narrative practice." Adelaide, Australia: Dulwich Centre Publications.

17. Creswell C, Christie D, Boylan J(2001) Ill or Adolescent? Developing Group Work on an Adolescent Medicine Unit. Clin Child Psychol Psychiatr 6: 351-362.

18. Epston D (2008) Anti-anorexia/anti-bulimia: bearing witness. In: Epston D (Ed) Down Under and Up over: Travels with narrative therapy 169-191.

Copyright: $@$ 2016 Christie D. This is an open-access article distributed under the terms of the Creative Commons Attribution License, which permits unrestricted use, distribution, and reproduction in any medium, provided the original author and source are credited. 